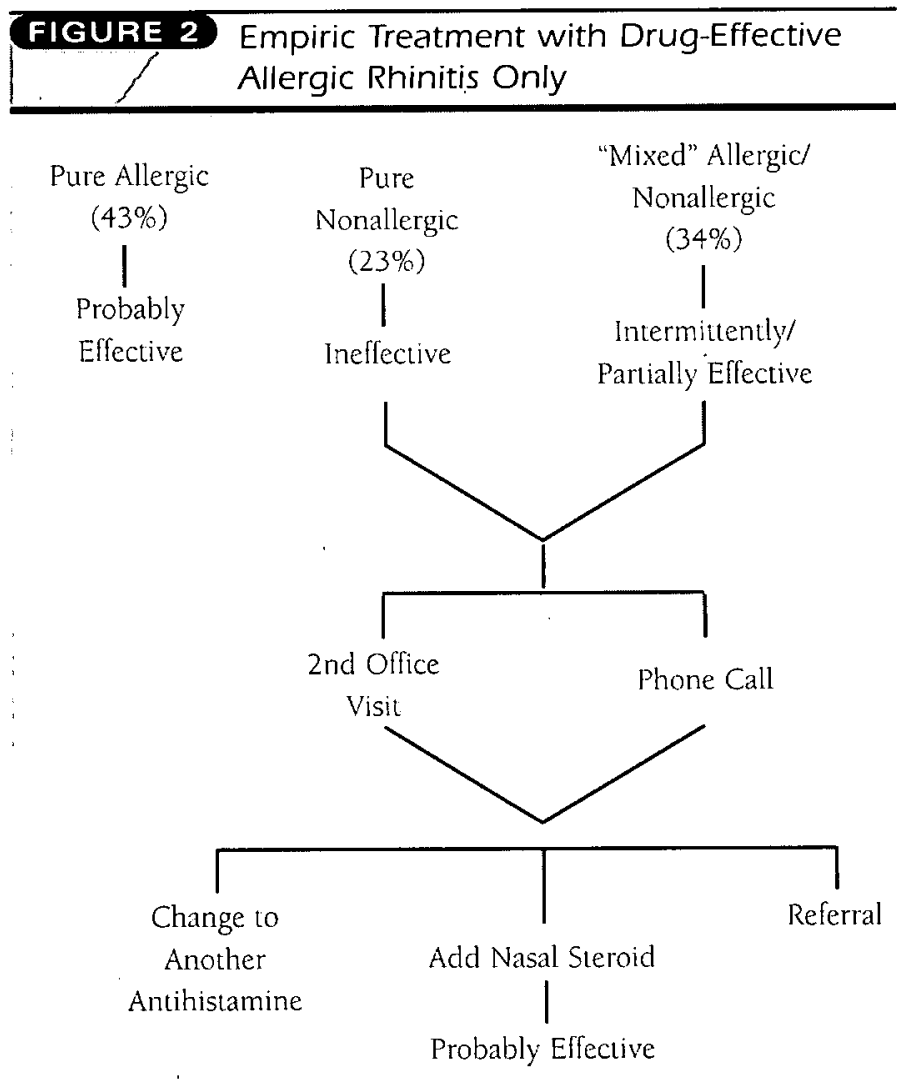

most appropriate treatment.

While this tool is not intended to be the sole determinant of a diagnosis, it may help patients understand their condition and know what outcomes to expect with treatment. Patients can identify their symptoms and pinpoint the months in which they occur. In addition to several helpful background questions about the onset and severity of symptoms, patients can identify factors that worsen their symptoms. The color-coded format makes the tool easy to read and interpret for both patient and physician.

\section{The Health Care Plan Perspective}

While The GMR Group was assessing the experience of managed care plans with rhinitis treatment, one group, Intermountain Health Care (IHC) in Utah, expressed great interest in managing the costs associated with rhinitis. IHC is comprised of 23 participating hospitals, 68 physician clinics and surgery centers, 360 employed community care physicians, and nearly half a million members.

Nonsedating second-generation antihistamines account for as much as $8 \%$ of IHC's prescription budget. In 2000, 45,000 members-nearly $10 \%$-were treated for rhinitis. While the national average for these medications was \$10.51 PMPY in 1999, IHC currently experiences a higher cost: $\$ 12.30$ PMPY. $^{20}$

The higher-than-average cost IHC experienced caused plan administrators to examine more closely how rhinitis is treated

\section{FIGURE 3}

Ideal Treatment Approach

Patient Presents With Rhinitis

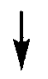

Determine Allergic, Nonallergic, or Mixed

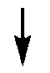

Remove Allergen/Trigger

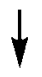

Treat Symptoms Appropriately

within the plan. Looking at both the National Rhinitis Classification Task Force survey results and the retrospective clatabase analysis, IHC administrators asked:

- Why is there such high use of antihistamines in diagnoses where it is inappropriate, such as acute sinusitis and common cold?

- How does increased time pressure affect our physicians' diagnostic practices?

- Can IHC reduce or eliminate inappropriate utilization of resources?

- How often does patient demand for a particular medication drive diagnosis?

Given the magnitude of cost experienced in this category, the pharmacoeconomic implications of the Tricore study and the work of the National Rhinitis Classification Task Force are significant. More appropriate use of products in this category may enable health plans to recognize substantial cost savings.

\section{Potential Solutions and a Pilot Program}

The pharmacy director at IHC (and in other plans that elect to undertake such an initiative) will play an integral role in developing and implementing strategic initiatives to improve the quality of patient care, examine current products on the formulary, control rising drug costs, and identify opportunities to improve patient care and better manage the cost of care for allergic and nonallergic rhinitis. The IHC pharmacy director is an advocate for finding a solution to the challenge of efficiently treating plan members suffering with rhinitis.

First, in a series of meetings with staff who would be working on the initiative, IHC identified four tactics to address the rising cost of treating rhinitis: sharing data with physicians; enhancing the diagnostic process through the use of a simple tool; educating patients, physicians, and employers; and implementing an intervention program.

These tactics then were incorporated into a pilot program designed to improve satisfaction for patients seeking treatment for rhinitis and for physicians who treat these patients, and to 
PATUENT RUUNUTUS SCREEN

This form will help determine the kind of rhinitis you have.

Please check the box next to your symptoms.

\begin{tabular}{|c|c|c|c|c|c|c|c|c|c|c|c|c|c|}
\hline \multirow[b]{2}{*}{$\begin{array}{l}\text { What symptoms } \\
\text { do you have? }\end{array}$} & \multicolumn{8}{|c|}{ When do you have symptoms? } & \multicolumn{4}{|c|}{$\begin{array}{r}\text { Age whon you } \\
\text { first started } \\
\text { having symptoms? }\end{array}$} & \multirow[b]{2}{*}{$\begin{array}{c}\text { All } \\
\text { year? }\end{array}$} \\
\hline & Jan & Feb & Mar & Apr & May & Jun & Jul & Aug & Sep & Oat & Nov & Dec & \\
\hline Sneezing & & & & & & & & & & & & & \\
\hline Stuffy nose/congestion & & & & & & & & & & & & & \\
\hline Runny nose & & & & & & & & & & & & & \\
\hline Postnasai drainage & & & & & & & & & & & & & \\
\hline Itchy eyes/itchy nose & & & & & & & & & & & & & \\
\hline
\end{tabular}

What medication(s) do you take for your symptoms?

Are your symptoms: $\square$ completely $\square$ controlled? $\square$ comewhat $\quad \square$ uncontrolled?

Patient: Please check all the things that you think make your symptoms worse:

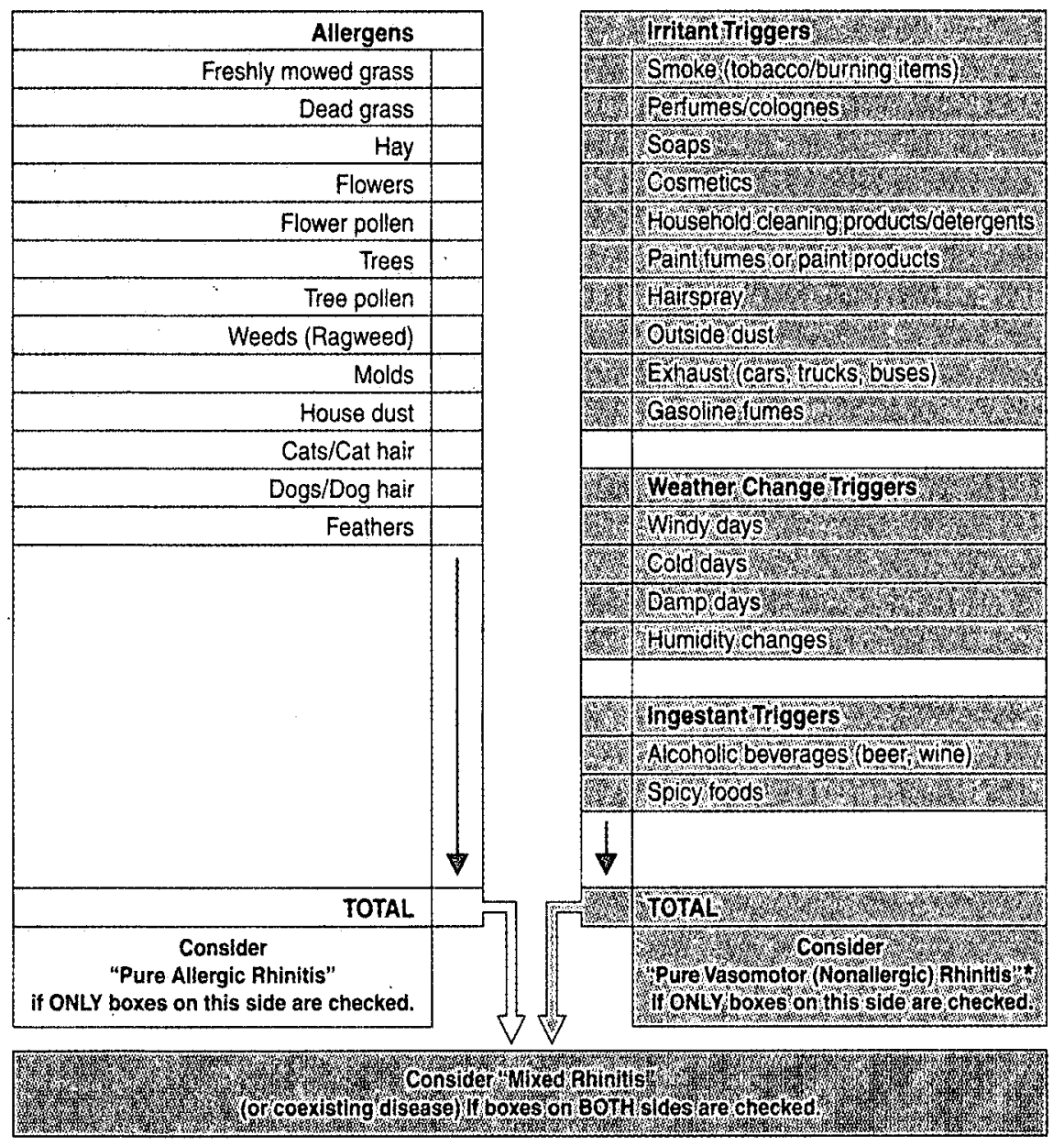

* Vasomotor minitis is the major type of nonatlergic minitis. Other types of nonallergic mintis include: infectious, hormonally-, exercise-, drug-, or reflex-induced etiologies, NARES and ciliary dyskinesia syndromes, and atrophic rhinitls. See guidolines by Dykowicz, et al for complete information (Ann Allergy Asthma Immunol. 1998;81:478-518). 
Define
Plan
Implement

Measure
Define objectives and values

Benchmark/segment total population

Identify target population

for Disease Management
Implement plan

- Communication

- Integrate tools

- Deploy

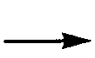

Reassess outcome measures vs. objectives and values

- Monitor

- Intervene evaluate the effectiveness of specific rhinitis disease-management techniques (see Figure 5, above).

IHC intends to first identify from 4 to 12 clinics that treat similar numbers of rhinitis patients and have similarly qualified physicians. These sites and physicians will be assigned to either a "usual care" group or the "disease-management" group. Once these are selected, patients will be selected, using pharmacy claims data, by whether they are receiving a target drug. Medical claims data will identify the ICD-9 diagnostic code recorded for each patient.

Surveyors will be looking for quantitative data, such as the percentage of patients using nasal steroids or antihistamines; the number of rhinitis-related office visits, the number of rhinitis-related medications per member per month; the percentage of patients who switch from medication to medication; and the impact on productivity, as measured by lost work days.

Other inquiries will look at patient and physician satisfaction with the disease-management program, patient knowledge about the disease, and the number of patients reporting disease-management problems (using a rhinitis-attack diary).

\section{Patient-directed Interventions}

The project offers a significant opportunity to educate patients and further integrate them into the treatment process. Patients will receive an initial mailing, containing material such as:

- a welcome letter explaining the participation selection criteria for the program;

- a brochure containing information about rhinitis and its treatment;

- a quality-of-life survey; and

- the Rhinitis Diagnostic Screening tool developed by Dr. Lieberman.

Patients will receive other mailings, including additional explanatory materials and periodic survey forms.

\section{Physician-directed Interventions}

Physicians who are members of the disease management group will receive an initial mailing, containing material such as:

- a welcome letter explaining the program;

- a list of rhinitis patients in their practice;

- copies of the patient-oriented material;

- a rhinitis diagnosis and management guideline; and

- the Rhinitis Diagnostic Screening tool developed by Dr. Lieberman.

Physicians will also receive follow-up mailings, keeping them informed about the study, including copies of information distributed to their patients by the managed care plan. Local educational programs will be designed to help physicians better help their patients.

IHC hopes that improving the differential diagnosis of allergic versus nonallergic rhinitis and better informing patients will result in more-efficient treatment and higher patient satisfaction.

\section{Summary}

Rhinitis is a very common disease, afflicting millions of people at great expense in medical care and prescription costs. Nearly half of all rhinitis patients exhibit symptoms that are either nonallergic or mixed, making it difficult for most physicians to diagnose the true nature of the disease. Symptoms of allergic and nonallergic rhinitis are often indistinguishable and the problem is compounded by current trends such as the demand for rapid diagnosis and direct-to-consumer advertising. Only a combination of close physical examination, focused patient history, and clinical testing can lead to a diagnosis that optimizes treatment.

Therapy is driven largely by primary care physicians, although there is a strong element of patient-driven therapy selection. Medications are often selected on an empirical basis, although these are often ineffective in addressing patient symp- 